DOI: https://doi.org/10.32839/2304-5809/2021-5-93-61

УДК 343.98 .062

Литовський О.Г., Шевченко С.М.

Харківський науково-дослідний експертно-криміналістичний центр

Міністерства внутрішніх справ України

\title{
ВИЯВЛЕННЯ, ВИЛУЧЕННЯ ТА УПАКОВКА СЛІДІВ РУК ПРИ ОГЛЯДІ МІСЦЯ ПОДІї
}

\begin{abstract}
Анотація. Розглянуті основні методи виявлення слідів рук, а саме візуально-оптичні, фізичні методи, фрізико-хімічні методи та хімічні методи. Аналіз обстановки місця події, загальний вигляд предметів, зміни, внесені злочинцем до первісної обстановки, і уявна їі реконструкція, а також вид слідів рук і місце їх виявлення - все це дає можливість вирішувати деякі питання в процесі попереднього дослідження слідів рук безпосередньо в ході огляду. Можливості виявлення слідів рук порошками, а також способи підготовки поверхонь перед використанням порошків, прийоми їх нанесення, особливості виявлення слідів рук за допомогою порошків на різних поверхнях. План рекомендацій які використовують при огляді місця події. Особливості опису виявлених та вилучених слідів папілярних узорів в протоколі слідчої дії. Правила пакування предметів зі слідами яких повинно дотримуватися, що виключають пошкодження або знищення слідів в процесі транспортування і подальшого зберігання.
\end{abstract}

Ключові слова: методи виявлення слідів рук, фротофіксація, дактилоскопічні порошки, пошук, вилучення та пакування слідів пальців рук.

Litovskiy Oleksandr, Shevchenko Sergiy Kharkiv Scientific Research Forensic Center of the Ministry of Internal Affairs of Ukraine

\section{DETECTION, EXTRACTION AND PACKAGING OF FINGERPRINTS AT THE CRIME PLACE}

Summary. Expanded based methods for examining hand modules, independent visual-optical, physiological methods, physicochemical methods and chemical methods. Analysis of the situation at the scene, the general view of the objects, the changes made by the criminal to the original situation, and its reconstruction, as well as the type of handprints and the place of their discovery - all this makes it possible to solve some issues in the process of preliminary examination of handprints directly during the examination. Possibilities of detecting handprints with powders, as well as methods of surface preparation before using powders, techniques for their application, especially detecting handprints using powders on various surfaces. Preparation of the powder for work and checking its quality should be carried out in laboratory conditions, and not during an inspection of the scene of the incident. The best powder is the one that brings out older hand marks. The following rules must be observed: do not handle wet, heavily soiled, sticky and greasy surfaces with fingerprint powders, and magnetic powders - also surfaces made of magnetic materials, including painted ones. In the description of the traces themselves, there should be their shape, size, general features of the papillary pattern and, if possible, other features that make it possible to individualize the detected trace to one degree or another. Further, the protocol indicates the method of fixing and removing traces: seized together with a slime carrier, photographed according to the rules of nodal and large-scale shooting, the scene of the incident marked on the large-scale plan, copied onto a fingerprint film of such and such a color. A plan of recommendations used when inspecting the scene of the incident. Features of the description of the identified and seized traces of papillary patterns in the protocol of the investigative action. The rules for packing items with traces of which must be adhered to, excluding damage or destruction of traces during transportation and subsequent storage. Correctly recorded and removed from the scene of the handprints make it possible to solve a crime even after a long time from the moment of its commission, which is not always possible by other types of traces.

Keywords: methods of detecting handprints, photographic recording, fingerprint powders, search, extraction and packaging of fingerprints.

Постановка проблеми. Вибір засобів 1 і прийомів, рекомендованих криміналістикою для пошуку слідів рук на місці події, багато в чому залежить від виду залишених слідів. Необхідно пам'ятати, що перед вилученням слідів їх потрібно сфотографувати за правилами масштабної фотозйомки. Основні труднощі виникають при пошуку маловидимих і невидимих потожирових слідів пальщів рук. Пошук починається 3 встановлення найбільш ймовірних місць знаходження слідів. Аналізуючи обстановку місця події і на основі такого аналізу спеціаліст висловлюе припущення, до яких предметів міг або повинен був торкатися руками злочинець. В процесі пошуку слідів рук необхідно проявляти осо- бливу обережність, щоб не знищити наявні на місці події сліди і не залишити свої. Сліди, залишені учасниками слідчої дії, можуть ввести слідчого в оману щодо їх походження, а в подальшому і експерта, якому буде доручено проведення дактилоскопічної експертизи.

Аналіз останніх досліджень і публікацій. Сліди папілярних візерунків пальців і долонь рук, що залишаються на місці скоення злочину, $\varepsilon$ найбільш поширеним і цінним джерелом індормації про особу злочинця. Це обумовлено їх добре вираженою індивідуальністю і незмінюваністю. Практика свідчить, що більшість криміналістичних експертиз і досліджень, що проводяться в експертно-криміналістичних підрозділах 
органів внутрішніх справ - дактилоскопічні. Правильно зафріксовані і вилучені з місця події сліди рук дають можливість розкрити злочин навіть після закінчення тривалого часу 3 моменту його вчинення.

Метою даної статті є освітлення способів виявлення слідів рук при огляді місця події, які методи використовують спеціалісти для виявлення слідів рук, план дій яких необхідно дотримуватися при виявленні та вилученні слідів а також їх упакування та опис в протоколі.

Виклад основного матеріалу. Пошук слідів рук в значній мірі визначається характером і обстановкою події, що відбулася. При огляді замкнутого місця події (квартира, приміщення, гараж, будинок і т.д.) в першу чергу звертають увагу на поверхні, яких злочинець міг торкатися, проникаючи в приміщення, перебуваючи в ньому та виходячи з нього. Перед виявленням слідів рук потрібно вжити заходів для того, щоб у час пошуку не знищити інші сліди, що є на об'єктах, i не ускладнити їх подальше дослідження (сліди взуття на підлозі, мікроволокна та сліди біологічного походження і т.п.) [2]. Слідчі ситуації настільки різноманітні, що, незважаючи на певні закономірності, дати вичерпний перелік всіх об'єктів, на яких можуть бути виявлені сліди пальців рук, і вказати, де саме вони можуть бути виявлені, неможливо. Оптимальною слід приймати рекомендацію пошуку слідів рук шляхом встановлення всіх об'єктів, з якими злочинець вступав в контакт. Об'єкти, на яких можуть бути сліди, треба брати таким чином, щоб не залишити своїх слідів і не пошкодити сліди злочинця. Вибір методів пошуку i виявлення слідів рук залежить, головним чином, від того, якою речовиною залишені сліди; від матеріалу, на якому ведеться їх пошук, i його структури, часу, що пройшов з моменту утворення слідів.

Сучасна криміналістика пропонуе наступні методи виявлення слідів рук:

- візуально-оптичні;

- фрізичні методи;

- фрізико-хімічні методи;

- хімічні методи [4].

Візуальні спостереження здійснюються неозброєним оком, з використанням приладів збільшення і з застосуванням різних засобів і методів освітлення. Візуально виявляються пофарбовані, вдавлені, поверхневі сліди, нашарування і відшарування, безбарвні потожирові сліди на глянцевих прозорих i непрозорих предметах. При џьому значну роль відіграють способи освітлення, найбільш характерні $з$ них засновані на використанні штучних джерел світла. 3 використанням спеціальних джерел освітлення (наприклад, ультрафріолетового освітлювача, лазера) можливе спостереження і невидимих слідів. Фізичні методи засновані на здатності речовин протягом певного часу зберігати адгезію, виборчу адсорбцію і можливість збудження люмінесценції. Безбарвні потожирові сліди залишаються на поверхні предметів, як правило, при будь-якому дотику пальців. Однак, не завжди такі сліди будуть ясно видимі і не у всіх випадках їх можна зробити видимими за допомогою існуючих техніко-криміналістичних засобів. Найпоширенішим способом виявлення безбарвних слідів рук є за- пилення їх порошками. Цей спосіб простий, не вимагає складної апаратури, застосуємо майже в будь-яких умовах і в багатьох випадках дає едективні результати. Для виявлення слідів рук використовуються магнітні і немагнітні порошки. Магнітні порошки виділяються в особливу групу у зв'язку з тим, що їх можна наносити за допомогою магнітного і звичайного ворсового дактилоскопічного пензля. При їх застосуванні менше ризик зіпсувати свіжі сліди, вони легко наносяться і легко видаляються 3 поверхні, не забруднюють приміщення.

Хімічні засоби у вигляді спеціальних реактивів застосовуються для виявлення слідів значної давності. 3 огляду на відому складність роботи 3 хімічними реактивами, виявлення слідів рук зазначеним способом слід проводити в лабораторних умовах, попередньо вилучивши сліди разом зі слідоносієм. 3 реактивів використовуеться азотнокисле срібло, нінгідрин та інші.

Фізико-хімічні засоби теж мають деякі переваги перед іншими способами виявлення потожирових слідів але в основному використовуються в лабораторіях [3].

При роботі зі слідами рук необхідно дотримуватися таких загальних рекомендацій:

- Перед початком огляду місця події необхідно з'ясувати вид злочину, спосіб і місце його вчинення; визначити вид огляду, необхідні технічні засоби; якщо огляд повторний або додатковий, ознайомитися з первинними матеріалами;

- На місці огляду детально досліджувати обстановку, з'ясувати початкове положення предметів, подумки провести реконструкцію; при необхідності ознайомитися 3 показаннями свідків, потерпілих, учасників огляду; визначити межі огляду, намітити послідовність роботи і точки фотозйомки;

- Особлива увага приділяється місцю проникнення, відходу злочинця і подолання їм різних перешкод;

- До огляду об'єктів необхідно виконати фотозйомку місця події, дотримуючись правил судової фротографіï; всі дії узгоджувати зі слідчим;

- Детально дослідити обстановку місця події та предмети, на яких передбачається наявність слідів рук; провести вузлову, детальну (масштабну) фотозйомку виявлених слідів;

- Оглядаючи і обробляючи об'єкти, дотримуватись правил обережності: тримати об'єкт так, щоб виключити пошкодження або втрату наявних і передбачуваних слідів; не залишати своїх слідів (рекомендуеться працювати в гумових рукавичках, а з дрібними предметами - за допомогою пінцета);

- При неможливості вилучити об'єкт зі слідами і необхідності обробки виявлених слідів рук важливо враховувати наступне:

вид, структуру і колір поверхні об'єкта;

давність утворення слідів рук;

можливість очищення поверхні від забруднень;

властивості використовуваних засобів.

- Підготовка порошку до роботи та перевірка його якості, повинні проводитися в лабораторних умовах і на полігонах, а не під час огляду місця події. Кращим порошком може вважатися той, який виявляе більш старі сліди рук.

- Не застосовувати незнайомі і недостатньо апробовані засоби. 
- Щоб уникнути псування або втрати слідів враховувати термін збереження і реакції потожирових слідів рук на проявники і дотримуватися таких правил:

Не обробляти дактилоскопічними порошками вологі, сильно забруднені, липкі і жирні поверхні, а магнітними порошками - ще й поверхні 3 магнітних матеріалів, в тому числі пофрарбованих. При обробці поверхонь об'єктів дотримуватися принцип: від не руйнуючих методів - до руйнуючих [1].

Виявлені і вилучені сліди рук докладно описуються в протоколі слідчої дії. Запис повинен містити відомості про місце виявлення слідів і особливості слідосприймаючого об'єкта (його колір, матеріал, з якого виготовлений, вологість поверхні і т.д.). Крім цього в протоколі вказується, за допомогою яких технічних прийомів і засобів сліди були виявлені (візуально при огляді конкретного предмета, за допомогою порошку конкретного найменування і кольору і т.д.).

В описі самих слідів повинні знайти відображення їх форма, розміри, загальні ознаки папілярного візерунка і по можливості інші ознаки, що дозволяють в тій чи іншій мірі індивідуалізувати виявлений слід. Далі в протоколі вказується спосіб закріплення і вилучення слідів: вилучено разом зі слідоносіем, сфотографовані за правилами вузлової і масштабної зйомки, відзначені на масштабному плані місця події, відкопійовані на дактилоскопічну плівку такого-то кольору і т.д.

Завершуеться опис слідів рук зазначенням на способи і засоби забезпечення їх збереження (упаковка та маркування) і відзначається фракт правильності записів, що відносяться до слідів. Запис з відповідними реквізитами робиться і на бирці, що прикріплюеться до кожного вилученого сліду [3].

Висновки. На підставі викладеного, можна підсумувати, що успішний пошук слідів пальців рук i долонь займає важливе місце при проведенні огляду місця події та залежить від вирішення організаційних питань підготовки до проведення огляду місця події і його виробництва. Пояснюеться це тим, що виявлення таких слідів безперечно свідчить, принаймні, про фракт перебування особи на місці злочину. А дотримання правил і рекомендацій при огляді місця події, істотно впливає на повноту і послідовність використання дактилоскопічної інформації в розкритті, розслідуванні злочину і встановлення злочинця.

\section{Список літератури:}

1. Методичні рекомендації по роботі зі слідами рук. URL: http:https://kriminalisty.ru/stati-metodikimetodicheskie-rekomendacii-po-rabote-so/ (дата звернення: 18.03.2021).

2. Способи виявлення, фріксації та вилучення слідів рук. URL: https://studme.org/120908107400/pravo/sposoby_ obnaruzheniya_fiksatsii_izyatiya_sledov_ruk (дата звернення: 02.04.2021).

3. Способи виявлення слідів рук. URL: https://studme.org/76343/pravo/sposoby_obnaruzheniya_sledov (дата звернення: 22.03.2021).

4. Методи що застосовуються для виявлення і вилучення слідів пальців рук та долонної поверхні. URL: https://studbooks.net/1157813/pravo/metody_primenyaemye_obnaruzheniya_vyyavleniya_sledov_paltsev_ ladonnoy_poverhnosti (дата звернення: 20.03.2021).

\section{References:}

1. Metodichni rekomendaciyi po roboti zi slidami ruk. Available at: http:https://kriminalisty.ru/stati-metodikimetodicheskie-rekomendacii-po-rabote-so/ (accessed 18 March 2021).

2. Sposobi viyavlennya, fiksaciyi ta viluchennya slidiv ruk. Available at: https://studme.org/120908107400/pravo/ sposoby_obnaruzheniya_fiksatsii_izyatiya_sledov_ruk (accessed 02 April 2021).

3. Sposobi viyavlennya slidiv ruk. Available at: https://studme.org/76343/pravo/sposoby_obnaruzheniya_sledov (accessed 22 March 2021).

4. Metodi shho zastosovuyutsya dlya viyavlennya i viluchennya slidiv palciv ruk ta dolonnoyi poverhni. Available at: https://studbooks.net/1157813/pravo/metody_primenyaemye_obnaruzheniya_vyyavleniya_sledov_paltsev_ ladonnoy_poverhnosti (accessed 20 March 2021). 